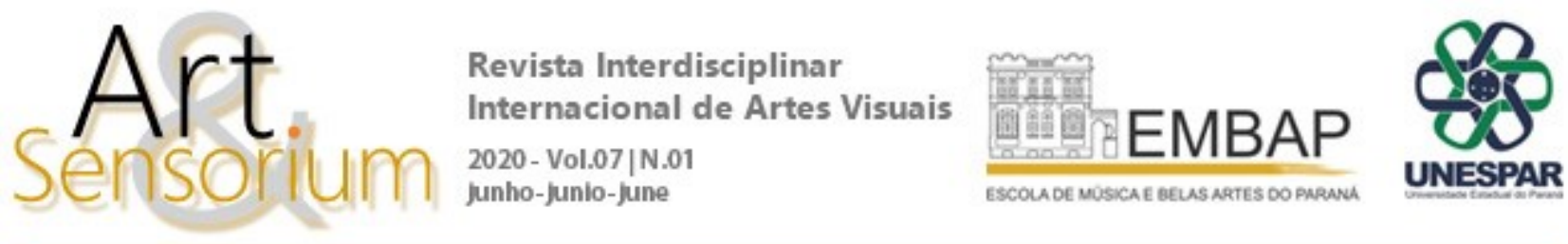

\title{
ENTRE SONHO, SAUDADE E LIBERDADE: A ESPONTANEIDADE DO FAZER SER ESTRUTURADO
}

DOI: https://doi.org/10.33871/23580437.2020.7.1.290-301

Bruno Leal Piva ${ }^{1}$

\begin{abstract}
Resumo: O presente ensaio trata sobre o fazer artístico em um universo contemplado entre sonho, saudade e liberdade pessoais. Inspira-se em vivências reais, em ações espontâneas, mas totalmente estruturadas pela artificialidade performática proposta dentro do espaço acadêmico. Procurou-se observar a fundo questões relacionadas a memórias, inconsciente coletivo e experiências próprias, conduzidas nas vertentes da referida tríade. Para tanto, não bastou apenas revelar intenções por improvisações momentâneas ou imediatas, mas tentou-se verificar como a estrutura é fundamental para emoldurar as ações espontâneas do instante-agora no formato artístico.
\end{abstract}

Palavras-chave: Fazer artístico; Sonho, saudade e liberdade; Inconsciente coletivo; Strindberg; Beckett.

\section{BETWEEN DREAM, NOSTALGIA AND FREEDOM: THE SPONTANEITY OF DOING BE STRUCTURED}

\begin{abstract}
The present essay focus on the artistic making in a universe contemplated between dream, nostalgia and personal freedom. It is inspired by real experiences, spontaneous actions, but totally structured by the performative artificiality proposed within the academic space. It was tried to observe in depth questions related to experiences, memories and own wills, conducted in the slopes of the said triad. For this purpose, it was not enough to reveal intentions for momentary or immediate improvisations, but it was tried to verify how the structure is fundamental to frame the spontaneous actions of the moment-now in the artistic format.
\end{abstract}

Keywords: Artistic making; Dream, nostalgia and personal freedom; Collective unconscious; Strindberg; Beckett.

\section{ENTRE SUEÑO, ANHELO Y LIBERTAD: LA ESPONTANEIDAD DEL HACER SER ESTRUCTURADO}

Resumen: Este presente ensayo trata acerca del hacer artístico en un universo abarcado entre sueño, anhelo y libertad personales. Se inspira en vivencias reales, em acciones espontáneas, pero

\footnotetext{
${ }^{1}$ Ítalo-Brasileiro Bacharel e Licenciado em Letras (Português/Espanhol) pela Faculdade de Filosofia, Letras e Ciências Humanas da Universidade de São Paulo. Professor de Línguas Portuguesa e Espanhola e Ator com formação e passagem pelo Estúdio de Treinamento Artístico, Cia Os Satyros, Escola Livre de Teatro, Grupo XIX de Teatro e Centro de Pesquisa Teatral de Antunes Filho. Mestre em Artes Cênicas na Faculdade de Ciências Sociais e Humanas da Universidade Nova de Lisboa. https://orcid.org/0000-0002-5145-8391. Mestre em Artes Cênicas pela Faculdade de Ciências Sociais e Humanas da Universidade Nova de Lisboa. e-mail: brulepi@gmail.com
} 
totalmente estructuradas por la artificialidad performativa propuesta dentro del espacio acadêmico. Se buscó observar a fondo cuestiones relacionadas en las vertientes de la dicha triada. Para estos fines, no se bastó solo revelar intenciones por improvisaciones momentáneas o inmediatas, pero se intentó verificar como la estructura es fundamental para enmarcar las acciones espontâneas del instante-ahora en la forma artística.

Palabras-llave: Hacer artístico; Sueño, anhelo y libertad; Inconsciente colectivo; Strindberg; Beckett.

\section{Introdução - ou Ponto de partida}

O desafio foi lançado. Quando foi perguntado ao mestre se haveria uma linha de investigação para compor o objeto performativo a ser apresentado durante o seminário "Espaços Performativos", e se ele poderia partir do conceito de inconsciente coletivo proposto por Jerzy Grotowski, sua voz ecoou e fez-se presente, um presente, em palavras semelhantes a essas: "Talvez estejas tentando esconderte detrás de um conceito, ao invés de explorar-te e revelar tua narrativa pessoal...". Sim, esse era um desafio, cujo sentido do termo, para o próprio Grotowski, seria vida, "o confronto com o desconhecido", como cita Ludwik Flaszen (2010, p. 29).

Seria equivocado dizer que o inconsciente coletivo, não o defendido por Carl Gustav Jung - ainda que este também influenciara na composição da performance, no âmbito da psique individual -, não estivera presente, uma vez que o alvo seria a "possibilidade de influir sobre a esfera inconsciente da vida humana em escala coletiva" (GROTOWSKI, 2010, p. 51). No entanto, o ponto de partida foi o fazer, experimentar fazer tendo como mote uma experienciação pessoal e compartilhada em comunhão com as outras testemunhas sonhadoras. Era preciso estabelecer um compromisso com o futuro, propagada por uma experiência individual e ao mesmo tempo coletiva, em que todos seríamos conectados e despertados por uma reflexão sobre a nossa humanidade - ou a falta dela.

Para isso, foi necessária uma reflexão solitária anterior, que caminhasse inserida num processo constante, inacabado e repleto de ressignificações sobre o próprio objeto artístico. Foram precisos reencontros comigo e com o outro - ou a ausência dele -, para propiciar um processo criativo de reinvenção, numa via de aproximação e distanciamento, como ocorrem nos sonhos. Nesse momento, foi necessário dar atenção especial aos sonhos, inegavelmente sob influência de Jung, para essa busca incessante de um inconsciente pessoal que não está arraigado apenas numa existência individual, sendo assim limitado, mas que transita entre os planos pessoal e coletivo.

\footnotetext{
${ }^{2}$ Disciplina ministrada em Mestrado de Artes Cênicas da Faculdade de Ciências Sociais e Humanas da Universidade de Lisboa, em segundo semestre de 2018, pelo Prof. João Garcia Miguel.
} 


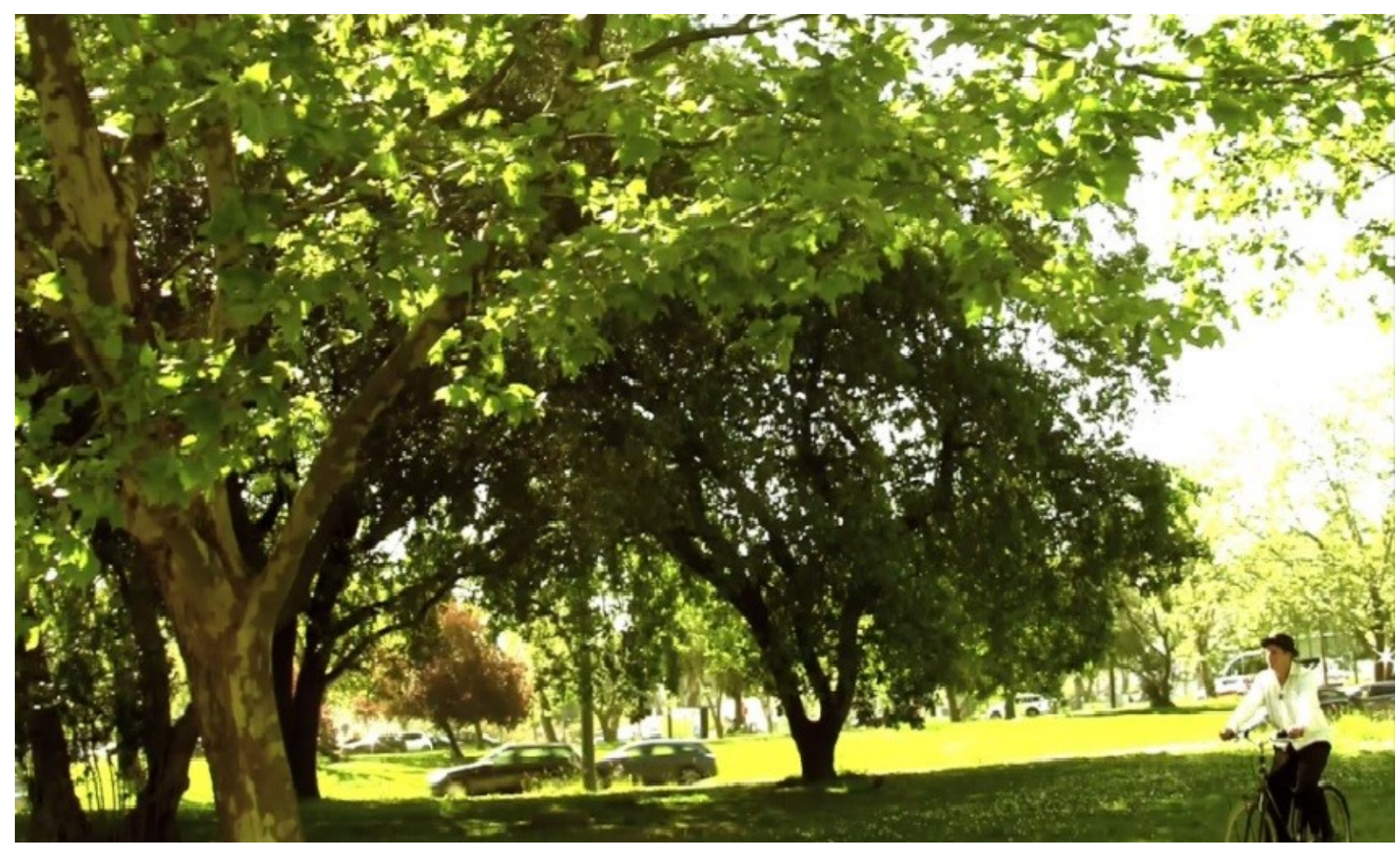

Figura 1 - Sonhos e movimento

A partir de então, da constatação de que os sonhos estavam a rondar ultimamente as noites mal e bem dormidas e de que eles moviam os passos rumo ao desconhecido, entre sol e neblinas, avenidas movimentadas, monumentos inesperados a cruzarem caminhos, aviões a decolarem, a faculdade e o academicismo a ressonarem em tons quase enigmáticos, a família identificada por filhos, pais e avós, entre outros, seriam eles motivo de compartilhamento em união com o fazer artístico, num movimento de contra tudo, contra todos e contra mim mesmo.

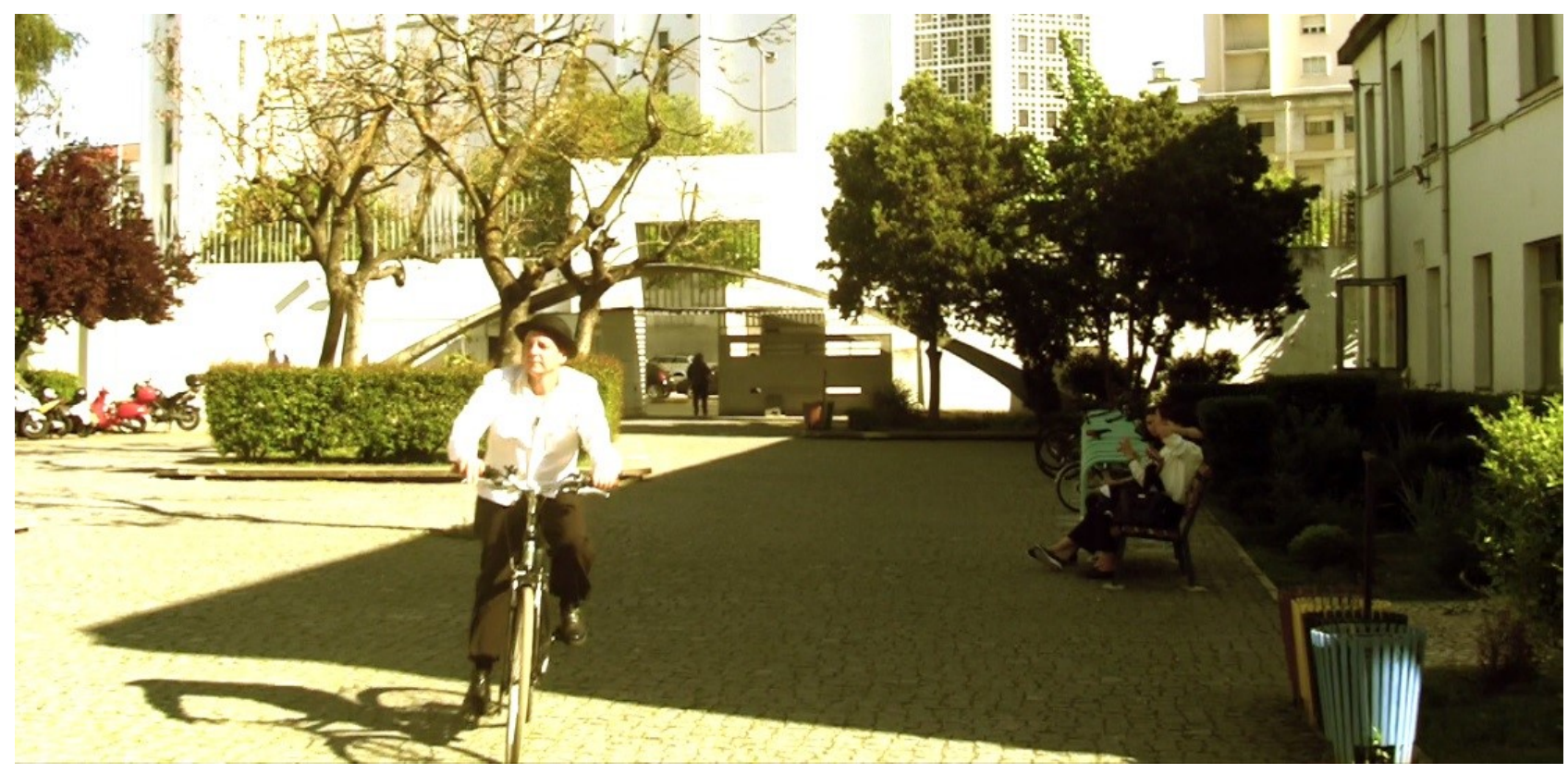

Figura 2 - Academicismo e fazer artístico

R. Inter. Interdisc. Art\&Sensorium, Curitiba, v.7, n.1, p. 290 - 301 Jan.- Jun. 2020 
Nessa luta que enfrentamos, há uma disposição contraditória, mas sutil, entre aquilo que almejamos para libertar-nos e as consequências dessa libertação: a saudade que chega de tempos outros, daquilo que nos desprendemos e do que, ao mesmo tempo, não queremos nos desprender. Trata-se de um combate travado entre passado, presente e futuro, uma tríade indissociável que caminha sem direção exata ou retilínea. A saudade dos que ficaram e impulsionam para o presente de ser livre, na projeção de um sonho futuro ainda não totalmente alcançado, o sonho que nos persegue e nos deixa persegui-lo, com e sem cobranças.

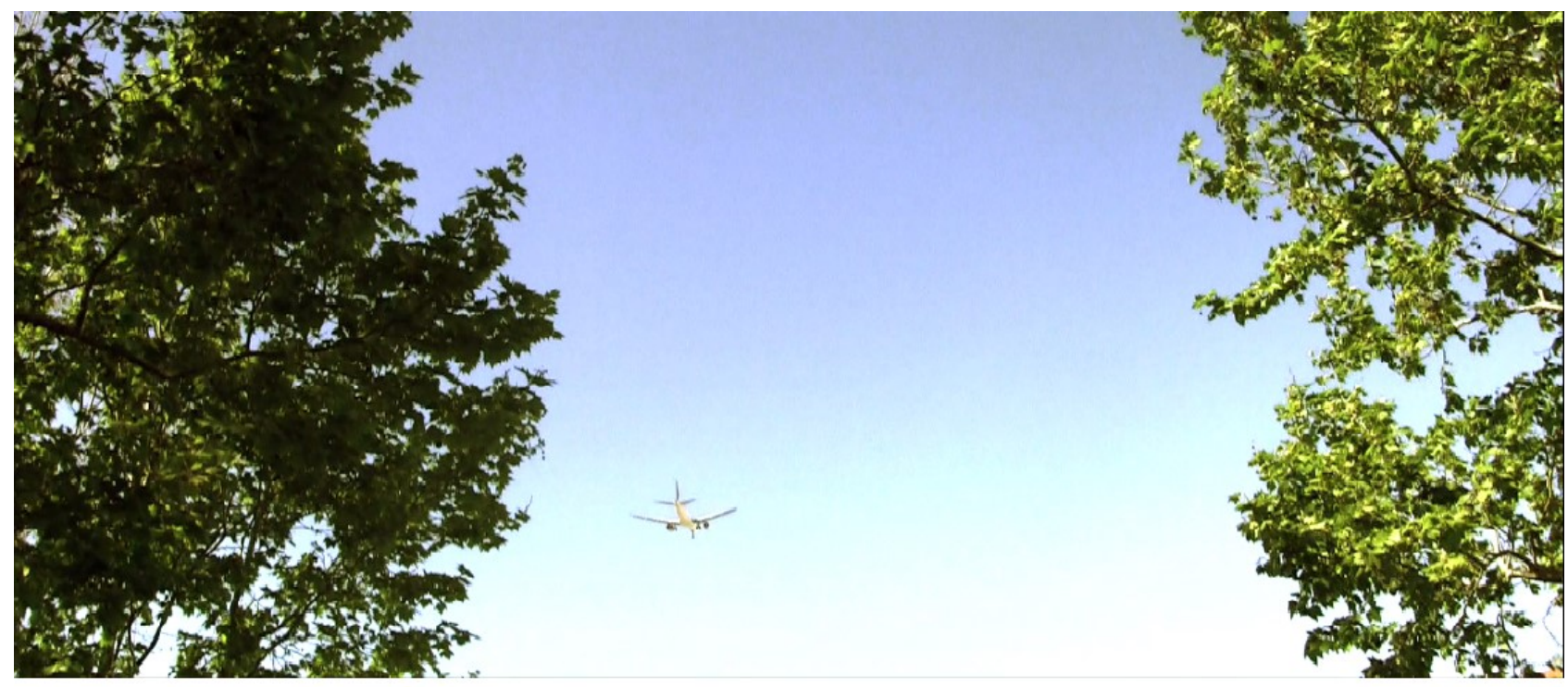

Figura 3 - Entre presente, passado e futuro

\section{As influências do fazer cênico}

A concepção de teatro pós-dramático poderia ser considerado a partir de Brecht ou Beckett, com o conceito de distanciamento e rompimento da ilusão da linguagem teatral, em que o espaço cênico não seria apenas um lugar de entretenimento ou relaxamento oferecido ao público. Os estudiosos acreditam que o poder das palavras - seja pela denúncia ou pelo seu esvaziamento - e a materialidade cênica como abstração racionalizada por eles aplicados, não se enquadra ao termo que dá nome ao principal livro de Hans-Thies Lehmann: Teatro Pós-Dramático (2007). No entanto, a discussão não deve girar em torno apenas ao que denominaria o teatro de todo o século $\mathrm{XX}$ ou do que dele resultaria, mas sim tentar verificar as diversas influências que o tornaram um teatro múltiplo e plural, sob o viés da presença do instante agora do ator, que se manifesta pela performance e como local onde se inscreve a memória coletiva.

Podemos iniciar a observação sobre esse novo teatro, com o advento do que pode ser denominado novo drama, em fins do século XIX. Os Georg (Buchner e Kaiser), Paul Claudel, August Strindberg, Antonin Tcheckov, Benjamin Franklin Wedekind, entre outros, já despontavam para um teatro que seria chamado de épico, do sonho, do eu, de situação. Atmosfera que envolve não por uma narrativa linear de costumes dominantes, mas que apreende por acontecimentos que situam o sujeito dentro de sua condição solitária, isolado dentro de uma subjetividade aparente individual. E tantos são os arquétipos esquecidos pelo turbilhão de tratados equivocados, que o homem se sujeita a não reconhecer nele próprio o universo inteiro e infinito que o compõe. 
Não se intencionou revelar facetas superficialmente estilhaçadas da constituição humana, por meio de recursos tecnológicos que iludem num prazer sinestésico imediato. Pretendeu-se explorar de modo súbito o desvelamento de caracteres presentes e ocultos na pluralidade do sujeito, mascarados por comportamentos sociais rotulados -, emergidos pela ausência de preocupação do resgate de sensibilidade, da preocupação de aproximar-se de si e do outro, de aprofundar-se em questionamentos das quais o cotidiano não nos permite refletir: a vontade de poder ser o que se ésomos-sonhos, desejos reprimidos expressados por uma existência representada não apenas num palco externo, mas num palco como espaço interno. E tomou-se por base para essa proposta o "drama de estações" citado por Anatol Rosenfeld (2000, p. 100), que pode melhor se ajustar à dramaturgia subjetiva de August Strindberg, capaz de epicizar impressões a partir do próprio íntimo, como o que ocorre em Rumo a Damasco, ou melhor dizendo, uma busca ao Desconhecido de encontro ao seu próprio Ego. Também houve como influência, ainda que inconscientemente, é verdade, À espera de Godot, de Samuel Beckett, com seus objetos simbólicos - o sapato, o relógio, os chapéus, o dinheiro, a mala, a árvore etc -, além do tempo e do espaço estáticos e simultaneamente mutáveis, em algum lugar, lugar nenhum, à espera de algo, espera nenhuma.

Nesse tipo de performance, em que o foco não se desencadeia em unidades de ações subsequentes e explicitamente justificadas, tem-se como relevância tempos e lugares exteriores ao drama, tornando-se as cenas "fragmentos cênicos de um romance", conforme cita Peter Szondi (apud Rosenfeld, 2000, p. 101). Ou ainda, pode-se dizer que a esse tipo de teatro revela-se um estado de alma numa espécie do que Rosenfeld (2000) chama de lirismo-monológico, aliado a uma experiência de solidão ou vazio a que Buechner (e eu) se depara - um caos social absurdamente individual. Acendeu-se, então, uma paixão entre o limiar do inconsciente consciente, uma interioridade expandida em toques dedilhados e delineados pela razão de se perceber como ser único e plural da ancestralidade carnal e espiritual, numa mistura entre recordações e vivências, muitas vezes absurdas. E a expressividade desse ser anônimo desejava materializar-se na iminência da queda que o abismo propõe a esse indivíduo formado por projeções de si mesmo, no instante teatral: encontra-se no fundo e também perde-se no mergulho, como num sonho, "desconexa, mas aparentemente lógica...", como cita Strindberg (apud Rosenfeld, 2000, p. 101-102), em seu Prefácio da obra $O$ Sonho.

Qual seria o papel do ator nesse plano de acontecimentos não necessariamente sucessivos a que se submete o ser humano durante situações imprevistas e mal calculadas? Como poderia situar-se dentro desse emaranhado de nós altos, médios baixos, contradições nossas de cada dia? Qual seria o espaço de reverberação daquilo que o aflige, acomoda, impulsiona, aniquila ou potencializa? Seria necessário identificar uma espacialidade exterior que o propulsionasse a expressar-se e a conectarse com o outro, ou estaria nele a espacialidade interior necessária para alcançar a sinceridade de ser com o outro o que todos, de alguma maneira, buscamos ou estamos condicionados a ser? Sonho, saudade, liberdade, nostalgia, melancolia...Esquecimento de sermos quem fomos, somos e podemos ser. Memória, revelação e transfiguração. E nos sonhos, é sempre o passado que não nos deixa, o futuro que ainda espera e o presente que não recebemos.

Pretendeu-se, por fim, realizar um deslocamento de si para fora, por meio de metáforas, elementos que suscitassem gestos e ações durante o processo do tecido performativo e conectassem-se ao inconsciente e consciente coletivos, valorização dos sonhos e a exploração da solidão humana caótica, ausência de palavras, uma criticização do ser-indivíduo inserido no mundo, nas suas particularizações engaioladas pela estrutura social que tolhe sua condição humana essencial, embora, ao mesmo tempo, necessite dessa sociedade em sua formação como ser indivíduo e social. E para essa realização houve inspiração em Andrei Tarkovsky, Lars Von Trier, Charlie Chaplin, Fernando Pessoa, Anton Tchekhov, Samuel Beckett, Friederich Nietzsche, Arthur Schopenhauer, Carl Jung, Sigmund Freud, Soren Kierkegaard, entre outros, com apoio teórico de estudiosos das 
artes, como os já citados Jerzy Grotowski, Hans-Thies Lehmann, Ludwick Flaszen, Anatol Rosenfeld e Peter Szondi.

\section{Saudade-liberdade-sonho: um mote trivial e triunfal}

Atenção especial aos sonhos. É nele em que me transporto para o irrealizável realizável. Cores, tons, sons, fumaças, barulhos, distorções, pessoas metamorfoseadas e híbridas que dispensam ações ininterruptas e sem sequência linear. Não há início nem fim: um ciclo misterioso sem desfecho, quase sempre guardado a sete chaves pelo inconsciente. Passei pelo monumento impetuoso, contemplando as portas de abril, que se abriram num ímpeto inesperado. Passeava, observava e via quão pequeno sou, mais do que costumo ser.

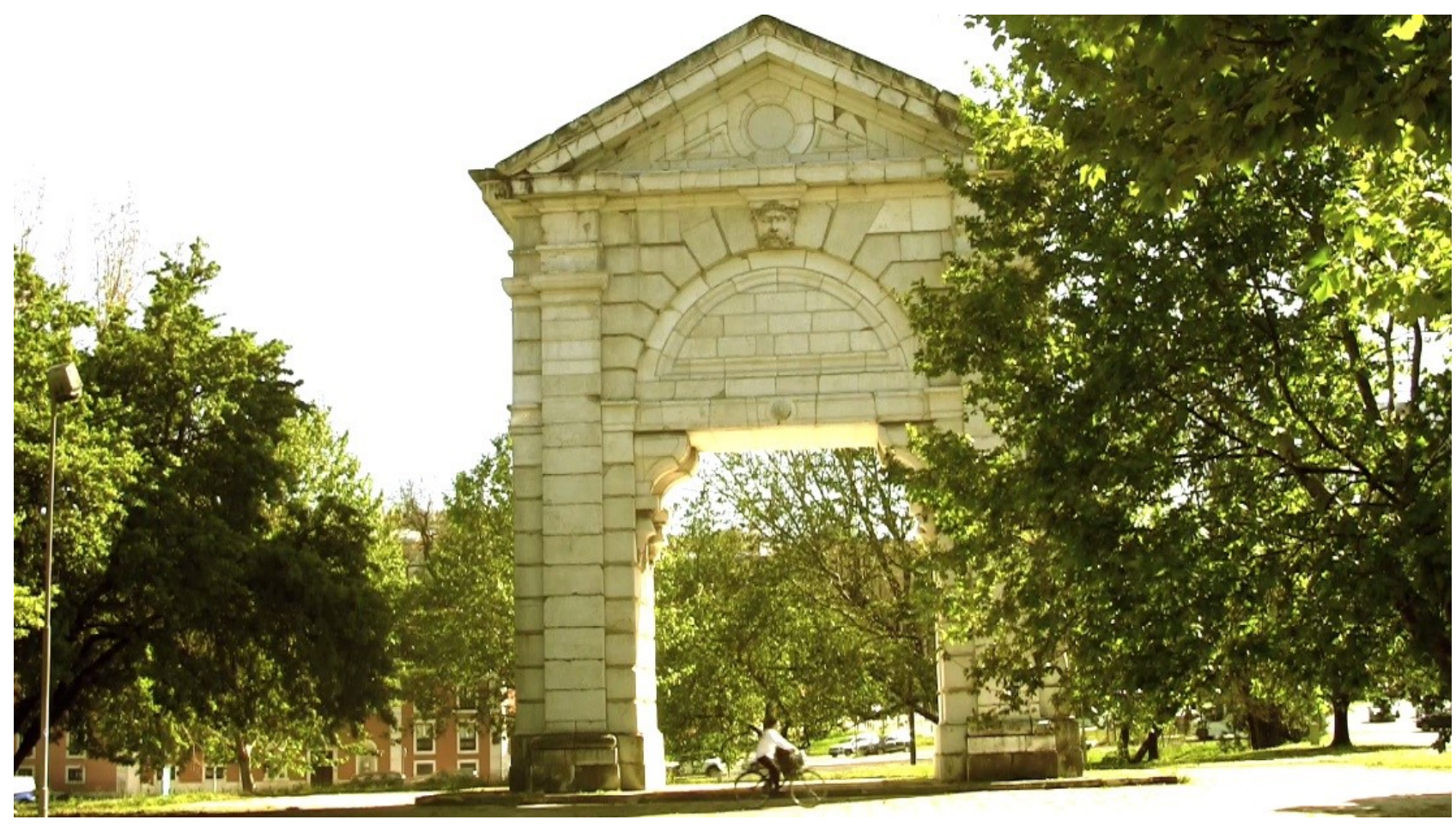

Figura 4 - Quão pequeno

Abriu-se um espaço para mim em mim. Seguia entre a multidão e continuava a conseguir espaço. Um espelho fragmentado em estilhaços que revelavam a multiplicidade do eu, como num filme de Tarkovsky. Poderia ser O Espelho (1975), Nostalghia (1983), O Sacrifício (1986), ou todos eles, compondo a unidade da criação artística na totalidade. Ou avançar para o estado de Melancholia (2011), de Lars von Trier. O caosmos instaurado na singularidade superficial do ser, tão perdido em seu universo. Tranquilo e aturdido. Perdido e emaranhado na busca infinita de uma identidade. Tentava libertar-me da humanidade, recluso em meu canto empoeirado num espaço impalpável. Viajava aturdido e carregava apenas um chapéu, uma mensagem e um cadeado preso ao pescoço. Ouvia e observava os transeuntes que hesitam em se reconhecer no reflexo de sua própria imagem. Andava em traços infinitos que acabavam em círculos, em cima da bicicleta, por não querer encontrar saída de meu sonho. O drama do eu. Não queria ninguém e queria a todos, não precisava nem dispensava ninguém, mas as companhias insistiam em se aproximarem ou em se manterem distantes. Strindberg inspira e eu decidi deixar a bicicleta em diagonal, a formar um triângulo com o banco e a fileira de lixeiras, atrapalhando a passagem de quem cruza, após avistar a mala esquecida em um banco fixado entre duas grandes árvores. Um espaço que soou poesia. Subi no banco em atitude rebelde e confiante, mas a mala trazia atração e repulsa, receio e curiosidade. Tracei uma 
reta imaginária e nela equilibrei-me, mas meus desequilíbrios são muitos. Joguei a mala ao chão, antes que eu caísse. Mas se caísse, levantaria.

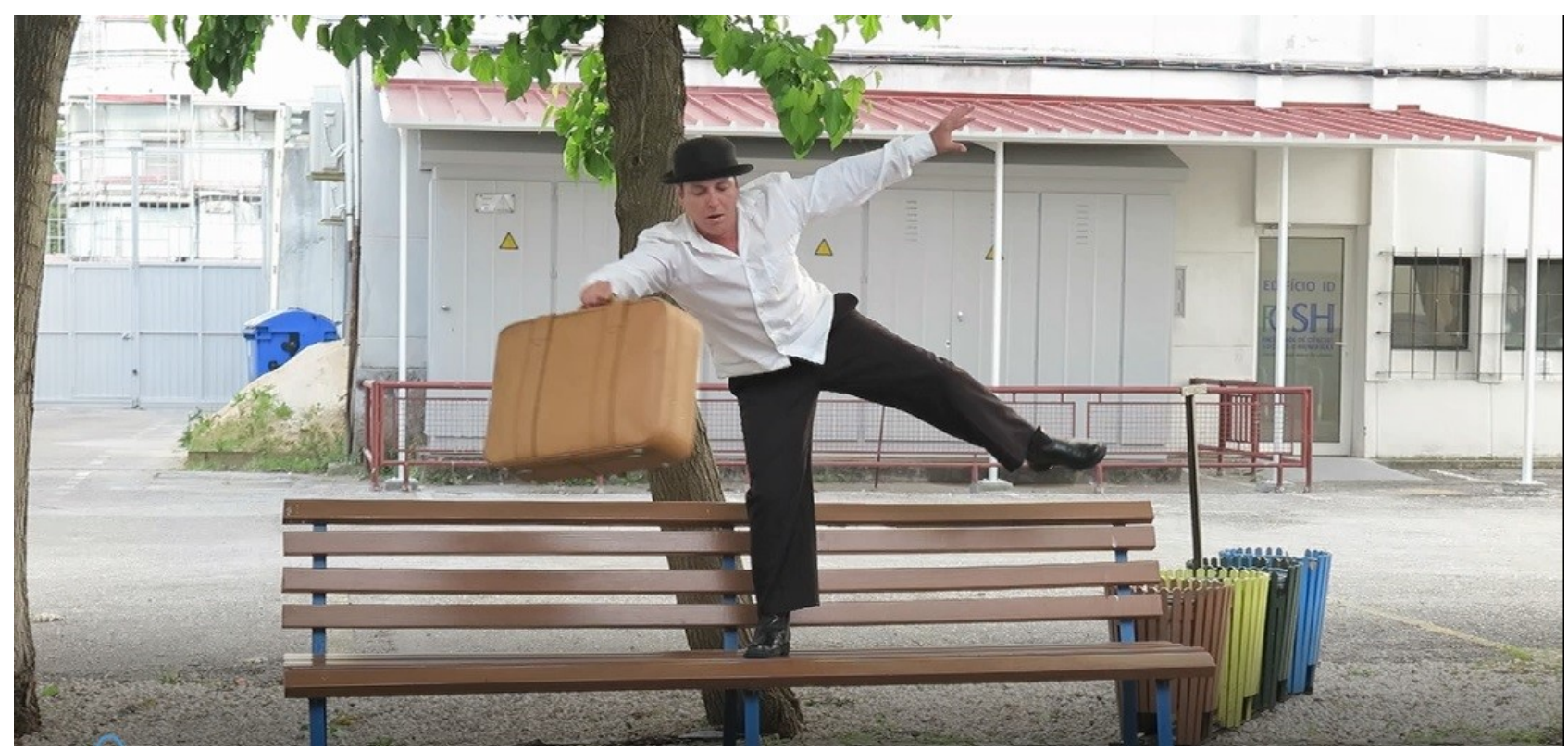

Figura 5 - Desequilíbrio

Não ofereci rosa a ninguém. Ofereci meu silêncio e o topor de meu Fortsvivlse (demasiada dúvida) diante da humanidade duvidosa e desesperançosa. Tinha vontade de feri-la, mas a ética não deixava. Tinha vontade de ridicularizar e expor a hipocrisia nossa de cada dia. Lembrei-me do pão de anteontem, endurecido pela ausência da mãe. Mas ninguém queria reparar na falta dos meus, apenas que eu me desvelasse e expusesse minhas fraquezas, medos, alegrias...A mala remetia a um esquecimento vivo, repleto de memórias e recordações. Trazia a saudade, que não se esconde nem se revela. Então esperava, não sabia pelo quê. Beckett que me perdoe, mas Godot que me esperasse! Talvez esperava pela venda da casa que o tio Vânia impediu de celebrar. Seria mais uma metafísica, metassonho, metateatro encenado sem roteiro. Mais uma vez lembrei de minha mãe, a protagonista da minha história, até o momento do enredo. Esqueci que havia um cachecol guardado, com a última gota de seu perfume. Cheirei-o, mas esqueci de como cheirava antes. 


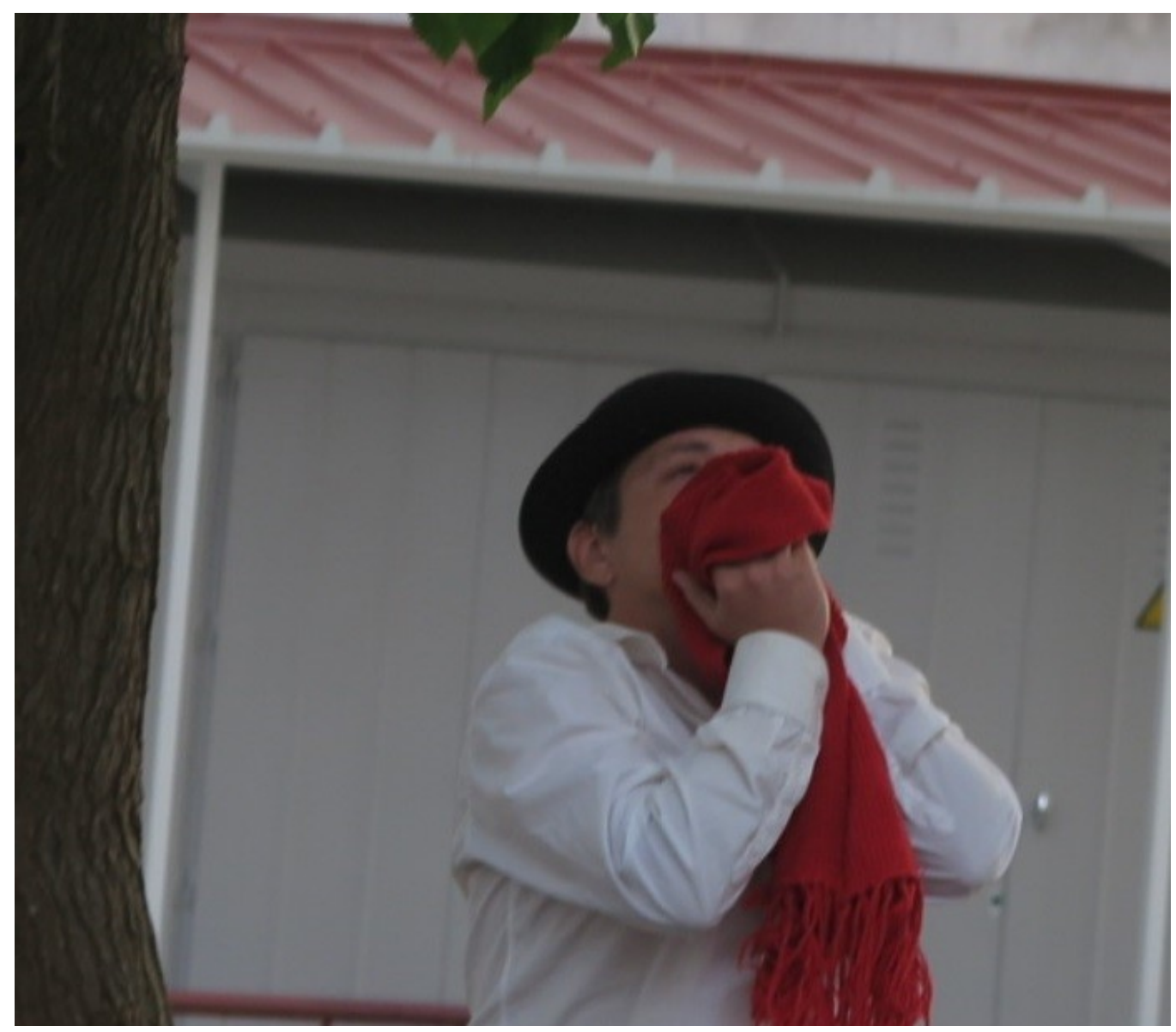

Figura 6 - Gota de perfume

Então, lembrei-me do tempo em que eu era criança, de como afagava-me em seu seio tão gentil, tão distante de mim. Com receio da ânsia, deitei-o fora, e ao invés da ânsia, veio a sede. Sede de que esse sonho se embebedasse com uma deliciosa garrafa de champanhe, inspirando liberdade, e que estourasse num gozo. Estourou: finalmente pude compartilhar meu gozo com alguém que não fosse ela.

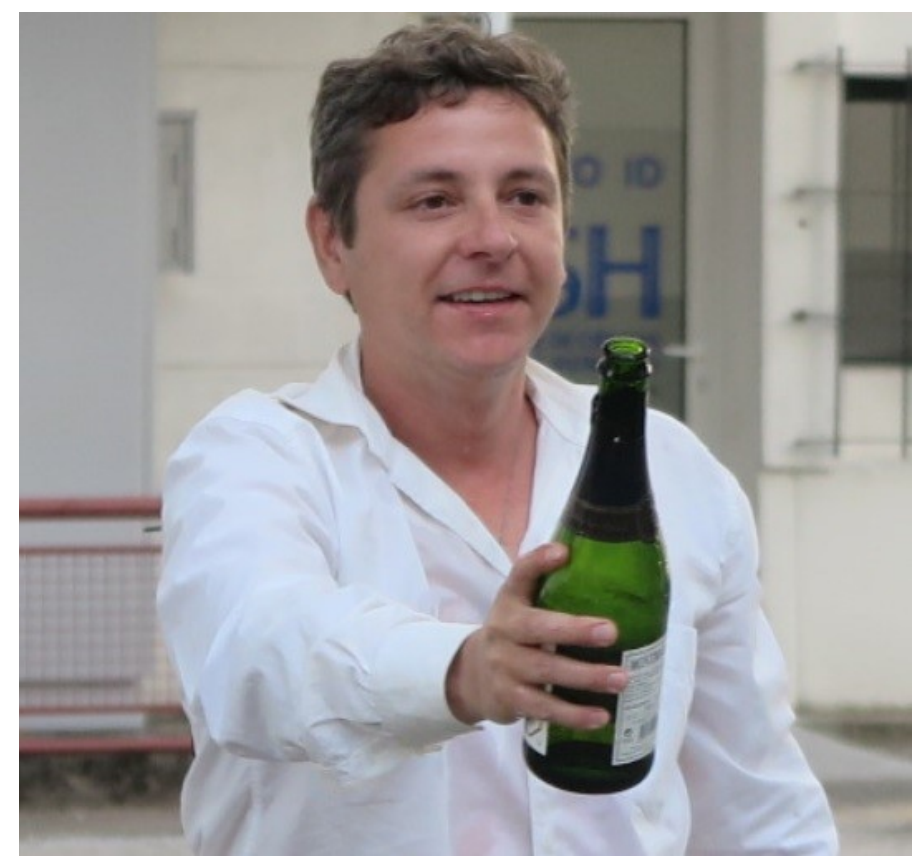

Figura 7 - Gozo

R. Inter. Interdisc. Art\&Sensorium, Curitiba, v.7, n.1, p. 290 - 301 Jan.- Jun. 2020 
Sempre dizem que Sigmund Freud explica. Naveguei em meus segundos quase de morte. Esquecime também do relógio banhado a ouro que herdara de meu avô, entregue por meu pai, estático no tempo presente da mesma hora. E não havia saudade que suportasse, tampouco a Nostalghia (1983) de Tarkovsky dava conta, mas evoluía para a Melancholia (2011) de Lars Von Trier, em rajadas de fogo mergulhadas na gastrite nervosa de meu estômago. Resolvi jogar com o tempo fora, para o lixo, já que a boina de meu bisavô, perdera no último carnaval. Metamorfoseei-me em mãe, pai, avô e avó. Então, encontrei e passei o batom vermelho, brincando com a cor estampada no rosto. Ela também retrataria as surras levadas pela ânsia de liberdade. A mala podia esconder-me, mas preferi revelar-me. Atordoado pela descoberta de ser quem quiser ser.

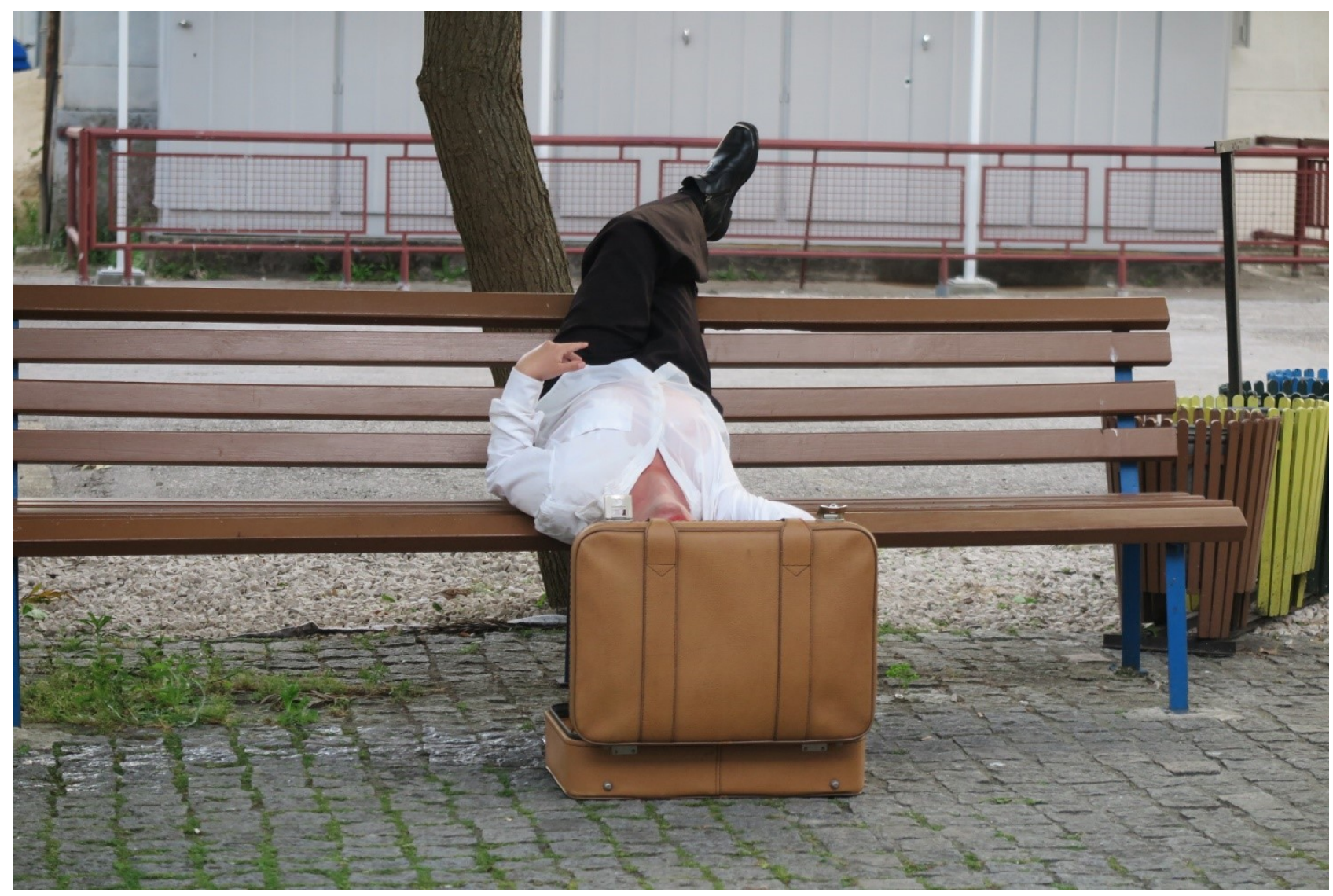

Figura 8 - Esconder-se é revelar-se

Lembrei-me do puto que me esperava. E a tão sonhada espera acalmava e levava-me a organizar meus pensamentos. E navegar é preciso, como diz Fernando Pessoa, mas viver só é possível quando se tem alguns tantos trocados no bolso ou no saco, entre tantas pessoas. Queria falar da chuva que ouço em mim e nas telhas próximas que não posso ver, mas não queria falar disso naquele instante. Resolvi estralar as moedas que pagam o nosso mingau, já que mingau não tem graça. Via graça enquanto me embebedava com grandes goladas que manchavam com gozo a única camisa branca, pela falta da taça de cristal. Quebrava-me e ria-me de mim e do mundo. Encontrei, finalmente, a caixa de música, mas ela não tocou a Tosca Tango Orchestra. Tocou em mim e ressoou a voz grave de alguém que eu não esperava naquele momento, mas que eu sempre esperei. Em rebeldia, sentime aprisionado, pois não há nada nem ninguém que possa impedir a busca incessante pela liberdade. Fiquei preso entre troncos e remeti-me a uma tortura ancestral: surrado mais uma vez. Esbravejando, consegui livrar-me e encontrei a senha do cadeado que me acorrentava. Retomei mais uma vez as rédeas dos desafios da vida e recolhi o chapéu protetor dos meus cabelos que insistem em deixar-me. Com dificuldade, mas confiante, recolhi minhas coisas e corri atrás de mais sonhos, amparado pela saudade e pela liberdade, deixando para trás a bagagem pesada, num sonho 
abandonado por ilusões que o mar respira e assopra. Suspirei aliviado pela solidão de se estar só, sem ninguém, com nada, comigo, levado apenas pelo sopro que não hei de esquecer.

\section{Estrutura e espontaneidade para e do fazer}

A motivação do desenvolvimento do processo, como construção cênica, foi movido pela ideia de fragmentação do Eu: enquanto um agisse, o outro observaria, numa diluição de mim em direção para um encontro o outro, com o mundo. São múltiplas as identidades que nos formam e a complexidade para exteriorizar nosso íntimo pela arte é um desafio grande e prazeroso: as ações ou concepções da estrutura artística deveriam levar os espectadores a uma espécie de labirinto, a uma dimensão que abrisse brechas ou sugerisse pistas para sua percepção, levando-os a desconfiar de si mesmo no jogo. Entretanto, não seria possível colocar-me em contato com o interlocutor, se não houvesse um contato sincero comigo mesmo, um resgate de sensibilidade ou desvelamento que despertasse a espontaneidade ou "corpo-essência" a que se refere Grotowski (1990 e 2010).

Para tanto, foi preciso criar tensões entre aquilo que eu acredito, não acredito ou penso acreditar, gerando conflitos e abrindo lacunas para que espectadores preenchessem com seus sentidos. Ao mesmo tempo, era necessário não deixá-los distantes ou ficar a falar sozinho, na tentativa de propor um olhar individual e coletivo, na interação imediata e direta com todos. Como poderia estabelecer tal conexão? Através de um ato de sacrifício ou desnudamento, mostrando aspectos de mim mesmo como ato de provocação, com sinceridade, num ato de comunhão real e total, mas ao mesmo tempo protegido pela máscara de uma possível persona outra.

Assim, caminham em via de mão dupla a estrutura e a espontaneidade, rigorosamente viva, no revezamento entre o que faz sentido à experiência vivenciada e ao que necessita de forma para o não esvaziamento e queda ao caos, compondo uma dialética no ato do ator, como define Flaszen (2010, p. 30) a respeito da teoria de Grotowski:

$\mathrm{O}$ ato do ator compõe-se das reações vivas do seu organismo, da 'corrente dos impulsos visíveis' no corpo. Todavia, para que esse processo orgânico não se desvie no caos, é necessária a estrutura que o canalize [...] Essa presença simultânea de dois elementos opostos favorece a tensão interior que potencializa a expressividade do ator.

Procurou-se, nesse sentido, estabelecer essa relação no trabalho apresentado, partindo de uma elaboração prévia, uma artificialidade cênica, mas com empenho interior sustentado por associações íntimas, no instante do "aqui-agora" e na relação com o outro, transformando a ação do instante no fazer artístico.

Ainda, para não perder a tentativa de compreensão sobre a linha de trabalho almejada e o efeito a que se procurou provocar, e ainda sob influência de Grotowski, a oposição entre elementos ou sentimentos, como emoção e intelecto, Belo e Verdade, Apolínio e Dionisíaco, corpo e espírito, alegria e dor, não são contraditórios, mas complementares. Esse olhar de Grotowski (2010, p. 106) revela que "Não há contradição entre a técnica interior e a artificialidade [...] Acreditamos que um processo pessoal que não seja sustentado e expresso por uma articulação formal e por uma estruturação disciplinada do papel não é uma liberação e cairá na falta de forma." Desse modo, a composição artificial não limita o que é espiritual, mas conduz a ele: "é uma armadilha munida de isca à qual o processo espiritual responde espontaneamente e contra a qual luta." (2010, p. 106-107) 


\section{Conclusão - ou Ponto de chegada}

Existe nessa busca por sonhos e liberdade, inspirados pela saudade, um ponto de chegada? Não, não há. Há apenas o processo vivo de continuar, de subir, decolar e pousar, entrar no ciclo do eterno retorno, dando voltas e a girar. Nesse movimento circular, há muito para arriscar, mas sem pressa para chegar a algum lugar. Na bagagem importa apenas o essencial, carregada com serenidade e com o intuito de preparação para mudar de direção - mais uma vez, induzindo à limitação real do próprio olhar sobre a totalidade da ilusão satisfatória do mundo, numa espécie de aprisionamento e autocensura que se cerram sobre si mesmo.

Aspira-se por liberdade, o presente que escorre pelas mãos, e conflita-se com o passado, pela saudade que insiste em bater, mas que também propulsiona novas vivências e experiências que os sonhos não tolhem. É a tríade passado-presente-futuro refletida pela saudade-liberdade-sonho, respectivamente, e que se converte em imagens interiores profundas, revelando impactos supostamente desconexos, mas profundamente enraizados numa relação íntima atuada de forma intuitiva, embora também organizada, num jogo de vai e vem que é sustentado pelo inconsciente coletivo inicialmente pessoal e que se propaga a todas as testemunhas presentes

Entender o mecanismo de criação do performer auxilia na captação do universo do outro e, desse jeito, transforma e acrescenta no universo subjetivo de si mesmo. Essa tentativa é um desafio de se estar ativo e passivo na arte, agindo e escutando, realizando e permitindo afetar-se, trocando experiências e olhares sobre a vida, na esperança de sua transformação. Cada um pôde, durante o processo do seminário "Espaços Performativos", ora revelar-se, ora ocultar-se, mas a ambiguidade também é recurso transcendental que contribui para a qualidade da criação performativa. E cada um sabe - ou acredita saber, ou não quis acreditar - o ponto que alcançou ou esperava alcançar. Mas até que ponto esperam algo de nós? Há alguém que espera? O que espera? Haverá alguém que nos espera? Há alguma espera? Não há verdades absolutas nem respostas corretas, mas apenas a chance de explorar o corpo-memória em vias opostas complementares, a chance de fazer valer a pena estar em contato consigo e com outro, num trabalho sincero do fazer artístico.

\section{Referências Bibliográficas}

BECKETT, Samuel. À Espera de Godot. Lisboa: Cotovia, 2001.

BROOK. Peter. (1970). O teatro e seu espaço. Petrópolis: Vozes. Edição digital em $<$ www.desvendandoteatro.com>. Acessado em 14 de novembro de 2017.

CHAPLIN, Charles. (1918). Vida de Cão. Estados Unidos. Filme disponível em < https://www.youtube.com/watch?v=txSJDmt4u6Q>. Acesso em 14 de abril de 2018.

GROTOWSKI, Jerzy. (1997). Performer. In The Grotowski Sourcebook, Schechner, Richard e Wolford, Lisa (coords.), Londres e Nova Iorque: Routledge.

GROTOWSKI, Jerzy; FLASZEN, Ludwik; BARBA, Eugenio. (2010). Teatro Laboratório de Jerzy Grotowski, 1959-1969. São Paulo: Fondazione Pontedera teatro/Sesc - SP/Perspectiva.

HUSTON, John. (1965). Freud, Além da Alma. Estados Unidos. Filme disponível em < https://vimeo.com/138376755>. Acesso em 2011.

JUNG, Carl Gustav. (2008). O Eu e o inconsciente. Petrópolis: Vozes.

LEHMANN, Hans-Thies. (2007). O teatro pós-dramático. São Paulo: Cosac Naify. 
LINKLATER, Richard. (2001). Waking Life. Estados Unidos. Filme disponível em < https://vimeo.com/158012084>. Acesso em 23 de abril de 2018.

MEYERHOLD, Vsevolod E. (1992). Meyerhold: Textos Teoricos, Edição de Juan Antonio Hormigon, Serie: Teoría y práctica del teatro. $\mathrm{N}^{\mathrm{0}} 7$, Publicaciones de la Asociación de Directores de Escena de España, Madrid 1992.

ROSENFELD, Anatol. (2000). O Teatro Épico. São Paulo: Editora Perspectiva.

RYAN, Bartholomew. (2016). Intervalos, Interseccionismos e a Pluralidade do Sujeito, in Nietzsche e Pessoa: Ensaios (ed. Ryan, Faustino, Cardiello), Lisboa: Tinta-da-China.

\section{(2015). The Plurality of the Subject in Kierkegaard and Nietzsche: Confronting}

Nihilism with Masks, Faith, and Amor Fati, in Nietzsche and the Problem of Subjectivity, ed. Branco, Constâncio, Ryan, Berlin/ New York: de Gruyter.

STRINDBERG, August. (1997). Rumo a Damasco. São Paulo: Cone Sul.

TARKOVSKY, Andrei. (1975). The Mirror. Rússia. Filme disponível em $<$ https://www.youtube.com/watch?v=9Yn9q25NWAw>. Acesso em 22 de novembro de 2017.

$$
\text { (1983). Nostalghia. Ítalia/Rússia. Filme disponível em }
$$

$<$ https://www.youtube.com/watch? $\mathrm{v}=\mathrm{oHeU5voLr3Q}>$. Acesso em 16 de abril de 2018.

(1986). $O$ Sacrificio. Suécia/Rússia. Filme disponível em https://www.youtube.com/watch?v=6WpA4WhPUqY. Acesso em 16 de abril de 2018.

TCHEKHOV, Anton. (2009). Jardim das Cerejeiras/Tio Vania. Porto Alegre: L\&Pm Pocket.

TRIER, Lars von. (2011). Melancholia. Dinamarca. Filme disponível em < https://pt.onmovies.to/film/d5a/Melancholia?ep=1_O1d5a>. Acesso em 2013. 